\title{
Good practice issues in psychiatric intensive-care units
}

\section{Findings from a national survey}

\author{
Stephen Pereira, M. Dominic Beer and Carol Paton
}

\begin{abstract}
Aims and method To survey some aspects of care relevant to good practice in psychiatric intensive-care units.

Results A number of areas of concern were identified, including care issues for informal and female patients, a lack of uniform clinical leadership and a paucity of policies/guidelines for high-risk areas of clinical practice.

Clinical implications in an attempt to provide a service for the most disturbed patients from widely varying sources, psychiatric intensive-care units are at risk of compromising the ability to provide good-quality clinical care.
\end{abstract}

Psychiatric intensive-care units (PICUs) contain the most acutely ill of all psychiatric in-patients. The doors of such units are almost always locked and levels of disturbance are high, resulting in the enforcement of 'safe' regimes involving loss of autonomy (e.g. removal of possessions, limited leave from the unit, restricted visiting, etc.). Given the rights of patients contained within the Mental Health Act, the Care Programme Approach and the Patient's Charter, in no other sub-speciality of psychiatry is the interface with legal, ethical, political and social factors more acute than with locked psychiatric intensive care. Yet, astonishingly, it is the one area within which these issues are most neglected. This is partly because intensive-care psychiatry is still in its infancy and has yet to attain a cogent force and status as a speciality in its own right. and partly due to custodial attitudes and other vestiges of institutional care that still prevail in these units (Zigmond, 1995).

Only recently have there been moves to establish a national network of PICUs in the UK. This network is now attempting to define the service that these units provide, and for whom, and the standard of care that is delivered within them.

During the first national survey of PICUs (Beer et al, 1997), general findings such as bed numbers, occupancy levels, staffing issues and the existence of clinical policies were quantified and discussed. This paper outlines in detail the findings from that survey pertinent to good practice issues, and the ability of the regimens on PICUs to compromise basic human rights.

\section{The study}

Questionnaires were sent to 397 pharmacists whose names were on the mailing list of the UK Psychiatric Pharmacists Group. If unable to complete the questionnaire, they were asked to identify their local PICU. Most questionnaires were followed up by telephone with PICU clinical staff (details are described in Beer et al, 1997). Only findings relevant to good practice issues are presented here.

\section{Findings}

Sixty-three (57\%) of the 110 units identified accepted informal patients. Of these, $49(45 \%)$ had no policy for rapid tranquillisation, 48 (44\%) accepted prison transfers, $46(42 \%)$ had their doors locked at all times, $18(16 \%)$ had no policy for control and restraint, $11(10 \%)$ had no seclusion policy (and did use seclusion), and eight $(7 \%)$ had beds currently occupled by forensic patients.

Seventy-two of the 110 units accepted a mix of intensive-care and chronically disturbed (challenging behaviour) patients. Seventy-two units accepted prison transfers; of these, 25 (35\%) had no policy for searching patients or visitors and $20(28 \%)$ had a male/female ratio of $5: 1$ or more.

Twenty units did not have an admissions/ exclusion policy, 29 units did not have a consultant psychiatrist with overall responsibility for the unit and 72 units either had no dedicated junior doctor or had a potentially inexperienced senior house officer. 


\section{Discussion}

\section{Informal patients}

General clinical impressions would suggest that all patients admitted to PICUs are detained under the Mental Health Act, and this is supported by the informal observations of Zigmond (1995). However, our survey shows that a significant proportion of PICUs accept informal patients. Although there may be sound clinical reasons for this, it does raise the issue of the rights of informal patients, such as their autonomy in terms of freedom to access leave off the ward, to keep their own possessions and to receive visits from relatives. Informal patients do not have their treatment reviewed by any third party, and continued consent to residence and treatment in such patients is often assumed. However, for such implied consent to be valid, the patient must accept treatment voluntarily and not under coercion. Several studies (e.g. Olin \& Olin, 1975; Grossman \& Summers, 1980; Applebaum et al, 1981: Wolpe et al, 1991) have found that psychiatric in-patients frequently did not understand their basic rights and issues relevant to informed consent. In a survey of 207 informal psychiatric patients in open wards (Sugarman \& Moss, 1994), almost half did not know that they had the right to refuse treatment. A substantial number anticipated being pressurised to stay, or being injected or restrained if they tried to refuse treatment or leave the ward. A substantial proportion of the PICUs in our survey did not have policies for rapid tranquillisation, control and restraint or seclusion. making it possible that the above fears of patients would be realised.

Due to a more proactive approach to identifying psychiatric disturbance in the penal system. such as court diversion schemes, a greater proportion of patients with either past histories of violence or with exposure to it are being admitted to PICUs (Atakan, 1995). In our survey, 48 units that accepted informal patients also accepted prison transfer patients, who by virtue of their sections had different leave arrangements to both patients detained under the Mental Health Act and informal patients. Issues of security also become relevant with the restrictions placed on remand patients. This invariably comprises the 'informal' status of the other nondetained patients on these units. Conversely, with a prison regimen, all inmates have basic rights to fresh air, exercise and seeing visitors. Receiving these 'rights' on PICUs is dependent upon adequate staffing levels and the general level of disturbance on the unit at any one time.

\section{Care of female patients}

Most would consider it unacceptable that within the locked confines of a PICU females find themselves in a very small minority. Besides the practical difficulties, such as the shared use of toilet and bathing facilities and the lack of privacy, potentially more serious problems such as sexual harassment can occur. In a survey by Barlow \& Wolfson (1997) of female psychiatric inpatients in open acute and rehabilitation wards. most (76\%) had experienced sexual harassment and $a$ few had been the victims of sexual assault. The majority felt that female-only wards and higher staffing would improve safety. Another study by Thomas et al (1995) reported that a similar proportion (71\%) of female in-patients had experienced unwanted physical and sexual experiences. Surveys of PICU in-patients have found that two-thirds of male patients admitted to PICUs were under 30 years of age and almost all were single, separated or divorced (Mitchell, 1992). Levels of disturbed behaviour were high and the proportion of female patients was low. All of these factors may contribute towards an increased risk of female patients being intimidated or assaulted. This aspect needs to be highlighted especially in newly built intenstvecare units, where provision can be made for grouping male and female bedrooms, tollet/bathing facilities and living areas separately. Some thought also needs to be given to redesigning facilities in existing PICUs. Working closely with local managers to make this happen is important. Indeed, there is some pressure from the government to move towards separate wards for male and female patients. The Patient's Charter (Department of Health, 1995) has incorporated the right of female patients to be admitted to femaleonly wards, but unfortunately extra resources will not be made available to implement this.

\section{Mixing acutely and chronically disturbed patients}

The majority of units accepted both long- and short-term admissions. This unsatisfactory $\mathrm{mix}$ of acutely and chronically disturbed patients with different clinical needs and treatment regimens is likely to lead to a poor compromise for all groups of patients. It is clinically well accepted that the longer term disturbed patient and the acutely disturbed patient require a different emphasis of care. For example: psychological and behavioural strategles are more appropriate interventions in the chronically disturbed than repeated episodes of rapid tranquillisation. It is difficult to deliver consistent care in the form of behavioural interventions in a unit that accepts a constant stream of short-stay acutely disturbed patients, a mix of informal and detained patients, as well as prison transfer and forensic patients. This places an enormous burden on PICU staff. Problems recruiting nursing staff and the variable composition of the multi-disciplinary team are known 
issues of concern in PICUs (Beer et al, 1997). Therefore, the therapeutic programme and other interventions are variable, with no accepted standards. One of the reasons for this wide variation may be because the inappropriate patient mix engenders a lack of focus in the nature of therapeutic interventions.

\section{Clinical leadership}

One-quarter of PICUs did not have a consultant with overall responsibility for the unit. This partly reflects the confusion of the role of a PICU within general services and most would argue that if specific and clear guidelines were in place for the use of a PICU then clear clinical and managerial leadership would ensure efficient and appropriate use of the facility. This has implications for the type of patients occupying PICU beds. It is clearly also inappropriate to have the majority of PICUs staffed by junior medical staff. Given the levels of disturbance, the use of high-dose medication and the other complicated issues that arise, doctors with a greater level of experience (MRCPsych and above) should provide input. Indeed, Zigmond (1995) recommended that junior medical staff must have training before being on call for such units.

\section{Unit/trust policies and clinical practice guidelines}

Psychiatric intensive-care units are high-risk areas from many perspectives. Levels of violence are high and many of the methods used to deal with it, such as rapid tranquillisation and control and restraint, have the potential to cause considerable harm in inexperienced hands.

Very often, junior doctors act on the advice of nursing staff, who they perceive to be experienced in a specialist area of care (e.g. where the use of emergency or high-dose medication is concerned). Surveys of trainees in psychiatry have shown inconsistencies and sub-optimal practice in the use of rapid tranquillisation (Mannion et al, 1997).

It is clearly inappropriate for a PICU not to have a policy for high-dose medication, either for rapid tranquillisation or for longer term treatment.

A significant minority of the PICUs surveyed did not have a policy for the practice of control and restraint or seclusion. This has implications for clinical practice. The Management of Health and Safety at Work Regulations (Health and Safety Executive, 1992) require hospitals to assess health and safety risks to employees, patients and visitors. Measures resulting from this risk assessment must be recorded, including adequate safety training. This, however, is impossible if clear policies do not exist for the standard practice of seclusion or control and restraint. Having clear policies for assessment and observation, with appropriate training in control and restraint procedures, can play a significant role in the reduction of violence in these units (Mortimer, 1995).

Examples of good practice for rapid tranquillisation have been described previously (e.g. Atakan \& Davies, 1997), and other examples of good practice guidelines in areas such as seclusion, control and restraint and the management of acutely disturbed behaviour have been published recently in the Royal College's Management of Imminent Violence (Royal College of Psychiatrists, 1998).

\section{Conclusion}

In the largest survey of PICUs in the UK so far, this paper has highlighted some of the issues relevant to good practice in these units. In an attempt to provide a service for the most disturbed patients from widely varying sources. good-quality clinical care may be compromised. This has implications for good practice. We would suggest that a centrally co-ordinated strategy of PICU provision via the Department of Health is essential to ensure more consistent good quality care nationally.

\section{References}

Applebaum, P. S., Mirkin, S. A. \& Bateman, A. L. (1981) Empirical assessment of competency to consent to psychiatric hospitalisation. American Joumal of Psychiatry, 138, 1170-1176.

ATAKAN, Z. (1995) Violence on psychlatric in-patient units: what can be done? Psychiatric Bulletin. 18. 593-596.

- \& DAVIES. T. (1997) ABC of mental health: mental health emergencies. British Medical Joumal. 314, 1740-1742.

BARLOW, F. \& WOLFSON, P. (1997) Safety and security: a survey of female psychiatric in-patients. Psychiatric Bulletin, 21, 270-272.

Beer. M. D., Paton, C. \& Pereira. S. (1997) Hot beds of general psychlatry. A national survey of psychiatric intensive-care units. Psychiatric Bulletin. 21, 142-144.

DEPARTMENT OF HEALTH (1995) The Patient's Charter and You. London: HMSO.

Grossman, L. \& SUMmers, F. (1980) A study of schizophrenic patient's ability to give informed consent. Hospital and Community Psychiatry. 31. 205-206.

HEAlth AND SAFETY EXEcutrve (1992) New Health and Safety At Work Regulations. Sheffleld: Health and Safety Executive.

Mannion. L.. SLOAN, D. \& Connolly. L. (1997) Rapid tranquillisation: are we getting it right? Psychiatric Bulletin. 21, 411-413.

MrTCHELl. G. D. (1992) A survey of psychiatric intensivecare units in Scotland. Health Bulletin. B0. 228-232.

MORTIMER. A. (1995) Reducing violence on a secure ward. Psychiatric Bulletin, 19, 605-608.

OuN. G. B. \& OuN. M. S. (1975) Informed consent in voluntary mental hospital admissions. American Journal of Psychiatry, 132, 938-941. 
Royal College of PSYchiatrists (1998) Management of Imminent Violence. Clinical Practice Guidelines to Support Mental Health Services (OP 41). London: Royal College of Psychiatrists.

SUGARMAN, P. \& MOSS, J. (1994) The rights of voluntary patients in hospital. Psychiatric Bulletin. 18. 269-271.

Thomas, C.. BARTLETT. A. \& MEzeY, G. C. (1995) The extent and effects of violence among psychiatric in-patients. Psychiatric Bulletin, 19, 600-604.

WOLPE, P. R., SCHWARTZ. S. L. \& SANDFORD, B. (1991) Psychiatric in-patients' knowledge of their rights. Hospital and Community Psychiatry, 42, 1168-1169.
Zigmond, A. (1995) Special care wards: are they special? Psychiatric Bulletin. 19. 310-312.

*Stephen Pereira, Consultant Psychiatrist, Dominic Beer, Consultant Psychiatrist, and Carol Paton, Principal Pharmacist, Oxleas NHS Trust, Bexley Hospital, Old Bexley Lane, Bexley. Kent DA5 2BW

*Correspondence

\title{
Open all hours: extending the role of the psychiatric day hospital
}

\author{
Judy Harrison, Amanda Poynton, John Marshall, Richard Gater and \\ Francis Creed
}

\begin{abstract}
Aims and method From March 1997, the acute day hospital in Central Manchester was extended to 24 hours, seven days a week, with patients treated entirely at home if preferred. The development and organisation of the new service are described. Preliminary evaluation data include service activity for the first 12 months and comparison with a consecutive series of in-patients during the first three months.

Results There was an increase in the number of patients treated in the first year $(n=214)$. Sixty-two per cent of patients suffered from schizophrenia. psychotic depression or bipolar disorder. Patients treated by the new service in the first three months $(n=43)$ were more likely than in-patients $(n=37)$ to have problems eating or drinking and to present with suicide risk, whereas the inpatients were more likely to have had adverse past experiences of services and to show behavioural disturbances.
\end{abstract}

Clinical implications the findings support the continued development of 24-hour alternatives to inpatient care, while emphasising that those requiring inpatient care have different presentations and needs.

\section{The original Central Manchester day hospital}

The Central Manchester day hospital was established in 1985, with a focus on acute treatment as an alternative to in-patient care. Early research on the use of the day hospital suggested that it was able to treat many patients who were as ill as those admitted to in-patient care (Creed et al, 1989). Subsequent randomised controlled trials of day hospital versus in-patient care showed that up to $40 \%$ of people presenting for admission could be treated successfully in the day hospital. with few differences in clinical or social outcome (Creed et al, 1990), and that the costs associated with day hospital care were significantly less than those for in-patient care (Creed et al, 1997).

Although the day hospital had successfully maintained a focus on acute treatment for over 10 years, staff were aware of a number of limitations. The service only operated from $9 \mathrm{am}$ to $5 \mathrm{pm}$ Monday to Fridays, leaving patients unsupported outside these hours. The addition of a limited weekend service during the second randomised controlled trial appeared to increase the severity of illness that could be treated successfully (further details available from the authors upon request). Although transport was provided and some home visits were offered, patients had to attend the base for at least some of their treatment and it was not possible to engage patients who preferred not to do so. There were also conflicting demands on the resources of the day hospital, such as group 